\title{
Professional Preparation Environment of Translator Training of China
}

\author{
Li Gao ${ }^{1,2, a}$, Hai-Tang Ren ${ }^{1, b,{ }^{*}}$, Xin Zhang ${ }^{1, c}$, Na Xu ${ }^{1, d}$ \\ ${ }^{1}$ College of Foreign Languages, Northwest University, Shaanxi, China \\ ${ }^{2}$ Institute of Education, Nanjing University, Nanjing, Jiangsu, China \\ aligao@nwu.edu.cn, brhait@126.com, cynthiazp@163.com, 'dxuna@nwu.edu.cn \\ ${ }^{*}$ Corresponding author
}

Keywords: Professional preparation environment, Translator training, MTI students.

\begin{abstract}
MTI (Master of Translation and Interpreting) program of China started in 2007 to prepare more professional translators and interpreters. The number of MTI institutions has increased rapidly in recent years. This makes it a must to examine the status quo of the programs. The present study borrowed the theory of educational research and surveyed the professional preparation environment (PPE) of translator training of seven institutions of China. 844 students' perceptions were collected and analyzed. It found that the status quo of the PPE was acceptable, but the condition of social environment, especially the status and income of translators, is far from satisfactory.
\end{abstract}

\section{Introduction}

The formal institutional translator training started from the 1940s[1] whereas in China it was until 2007 that Master of Translation and Interpreting (MTI) program was approved by the Commission of Academic Degrees of the State Council[2], which marked the beginning of first-ever officially approved program for professional translator training. Since then the past eight years have witnessed the fast growth of MTI programs nationwide. In 2007 the first batch of pilot programs was 15, and the number went up to 40 in 2008, 158 in 2010 and 206 in 2014[3]. This rapid growth of translator training programs may be worth cheering about and would bring a large number of graduates that may ease the problem of the shortage of qualified professional translators. However, it has been found that some MTI programs are still clinging to their former way of training MA research students in translation, and both the curriculum and pedagogy are not responsive to social or market needs [4]. Therefore the gap existing between the ideal of the program and the reality makes it necessary to examine the status quo of the MTI programs in China, especially at a time when more MTI programs are burgeoning.

\section{Conceptual Framework}

Literature reveals that the evaluation of translator training programs has been under-developed, and the bleak fact is that "education institutions hardy pay attention to translation course evaluation" [5]. Though some researchers [6] examined the effectiveness of translator training programs of Hong Kong in early $21^{\text {st }}$ century, empirical studies of translator training are still in its infancy [7], not to mention a systematic study of MTI programs in China.

Taking into consideration that translator training, like other professional education, is to train professionals, theory derived from the study of other professional degrees programs is borrowed here to present new angle in understanding MTI program. Similar to other researchers such as[5], the present researchers also takes an interdisciplinary approach and borrowed the notion of Professional Preparation Environment (PPE) from educational research.

The concept originally came from the research of Stark et al [8]. In 1980s students enrolled in professional degrees programs outnumbered those in liberal arts education and this initiated their study of different professional programs and it found that PPE was mainly influenced by three forces, namely external forces (society and professional community), internal forces (professional program itself) and intraorganizational forces (outside professional program but within college or university). The framework was later empirically tested by them and has been adopted by other 
researchers like [9] to examine the PPE of particular professional programs.

Based on this the present researchers also are interested in examining the PPE and translator training is focused on. In the context of translator training external forces are the influences of society and professional community on translators and translator training, i.e. educational policy, employment opportunity for translators, social status and financial reward of translators, employer engagement and the involvement of professional organizations in training translators. Internal forces come from MTI program itself and factors like educational background of faculty members, the structure and contents of courses, theory-practice ratio in translation teaching. Intraorganizational forces are institutional influence and factors like the mission and type of the institution, its location, academic culture, the importance of MTI program to university all play a role in this aspect.

\section{Research Design}

There are four main research paradigms in educational research, which are scientific and positivistic research, naturalistic and interpretative research, research based on critical theory and feminist education research. Our research is to verify the existence of PPE, understand its components, investigate its status quo and compare the differences in perception between different groups of MTI students and institutions, and the scientific and positivistic paradigm fits our research purposes better.

\section{Research questions}

To serve the purposes of the research the following research questions need to be probed:

What is the status quo of the PPE of translator training in China?

Are there any statistically significant differences in the perceptions of PPE between different groups of students and institutions?

\section{Population and sample size}

The identification and the size of the survey is a critical issue to consider and factors like expense, time and accessibility often prevent researchers from gaining information from the whole population. While it may not be realistic to survey all the MTI programs (206 in total), there is also no need to do so. A quick look at the programs shows that about one fourth do not have recruits until the autumn of 2015, and the rest can be put into two groups. One group, the majority of programs, offers two-year MTI programs and the other runs either two-and-a-half-year or three-year programs. Taking into account that the year of program plays an important part in the PPE and would influence the perception of students accordingly, we chose to focus on those MTI programs whose year of program is over two years, i.e. the programs that have the first-, second- and thirdyear students. This filters the population to a sample of seven institutions. Of them three are located in west China and they are Northwest University, Guizhou University and Xi'an International Studies University. Four are in east China and they include Shandong University, Nanjing University, Tianjin Foreign Studies University and Shanghai International Studies University. All the MTI students of the seven institutions were surveyed between late September and mid-October of 2014.

\section{Survey instrument}

The survey instrument was based on Stark et al [8] and a questionnaire was designed to incorporate the three forces influencing the PPE of MTI programs. It consists of two sections. Section One is a profile of survey respondents and has 12 items and they are all multiple-choice questions. Section Two collects the perception of the PPE of MTI students and contains 28 items. This section asks students to evaluate specific aspect of PPE they have experienced. The part of external forces comprises six items (h1-h6), intraorganizational forces has eight items (h7-h14) and internal forces 14 items (h15-h28). The scale is of the Likert-type with 1=completely disagree and $5=$ completely agree. The questionnaire can be found in Appendix.

Besides the administration of the questionnaire, a follow-up in-depth interview was also 
conducted after data analysis to validate the findings of the quantitative study and lend support in interpreting the results. A combination of stratified sampling and snowball sampling techniques was used in sampling. Three or four students from each study year were interviewed and the audio-recorded conversations were transcribed verbatim. Each interview lasted about one hour and was conducted at a time that was convenient for the interviewees. Also a small present was given after the interview as a token of appreciation.

\section{Data collection and analysis}

The administration of the questionnaire was conducted between late September and mid-October of 2014. Printed and electronic copies of questionnaires as well as cover letter explaining the purposes and the procedure of implementing the study were posted to the respective contact person of seven MTI programs. These contact people were either full-time teachers or administrators of MTI programs and have access to MTI students and are in a position to help bring a higher return rate of questionnaires. 844 questionnaires were sent and within two weeks (the recommended time) 685 questionnaires were returned, of which 602 ones had complete information and were analyzed. The returned rate was $71.3 \%$ and the distribution of the questionnaires and the characteristics of the respondents are in Table 1 and Table 2 respectively.

Tab.1 Distribution of Questionnaires

\begin{tabular}{|c|c|c|c|c|c|c|c|}
\hline \multirow{2}{*}{ Region } & \multirow{2}{*}{ Institution } & \multicolumn{2}{|c|}{ Printed Copies } & \multicolumn{2}{|c|}{ Electronic Copies } & Returned Copies & \multirow{2}{*}{ Percentage } \\
\cline { 2 - 7 } & & Sent & Returned & Sent & Returned & Total & 118 \\
\hline \multirow{3}{*}{$\begin{array}{c}\text { West } \\
\text { China }\end{array}$} & $\mathrm{A}$ & 103 & 89 & 47 & 29 & $17.1 \%$ \\
\cline { 2 - 8 } & $\mathrm{B}$ & 144 & 117 & 77 & 25 & 142 & $21 \%$ \\
\cline { 2 - 8 } & $\mathrm{C}$ & 41 & 39 & 18 & 12 & 51 & $7.4 \%$ \\
\hline \multirow{2}{*}{$\begin{array}{c}\text { East } \\
\text { China }\end{array}$} & $\mathrm{D}$ & 72 & 62 & 0 & 0 & 62 & $9 \%$ \\
\cline { 2 - 8 } & $\mathrm{E}$ & 80 & 62 & 0 & 0 & 62 & $9 \%$ \\
\cline { 2 - 8 } & $\mathrm{F}$ & 94 & 93 & 5 & 2 & 95 & $13.9 \%$ \\
\cline { 2 - 8 } & $\mathrm{G}$ & 122 & 116 & 41 & 39 & 155 & $22.6 \%$ \\
\hline Total & & 656 & 578 & 188 & 107 & 685 & $100 \%$ \\
\hline
\end{tabular}

Tab.2 Information of the Respondents

\begin{tabular}{|c|c|c|c|c|c|c|c|}
\hline Variable & Group & Sample & $\%$ & Variable & Group & sample & $\%$ \\
\hline \multirow[t]{2}{*}{ Gender } & Female & 506 & 84.1 & \multirow{4}{*}{$\begin{array}{c}\text { English } \\
\text { Proficiency }\end{array}$} & CET4 & 2 & .3 \\
\hline & Male & 96 & 15.9 & & CET6 & 63 & 10.5 \\
\hline \multirow{3}{*}{$\begin{array}{c}\text { Grade of } \\
\text { Respondents }\end{array}$} & Year One & 278 & 46.2 & & TEM4 & 17 & 2.8 \\
\hline & Year Two & 217 & 36.0 & & TEM8 & 520 & 86.4 \\
\hline & Year Three & 107 & 17.8 & \multirow{2}{*}{$\begin{array}{c}\text { Type of } \\
\text { University }\end{array}$} & Comprehensive & 275 & 45.7 \\
\hline \multirow[t]{2}{*}{ Part-time } & No & 471 & 78.2 & & Foreign Studies & 327 & 54.3 \\
\hline & Yes & 131 & 21.8 & \multirow{2}{*}{$\begin{array}{l}\text { Location of } \\
\text { University }\end{array}$} & West China & 270 & 44.9 \\
\hline \multirow{3}{*}{$\begin{array}{l}1^{\text {st }} \text { degree } \\
\text { university }\end{array}$} & Ordinary & 421 & 69.9 & & East China & 332 & 55.1 \\
\hline & Project 211 & 120 & 19.9 & \multirow[t]{2}{*}{ Major of BA } & Non-Englsih & 74 & 12.3 \\
\hline & Project 985 & 61 & 10.1 & & English & 528 & 87.7 \\
\hline
\end{tabular}

Software packages SPSS and AMOS were used to analyze the collected data and methods like descriptive statistics, item analysis, exploratory factor analysis, confirmatory factor analysis were applied where necessary.

\section{Findings}

\section{Reliability and validity of instrument}

The study was based on the conceptual framework of PPE [8] and the items of the questionnaire were designed accordingly. To test the reliability and validity of the questionnaire, the collected data was randomly equally split into two groups and each had 301 cases. One group was used for exploratory factor analysis and the other for confirmatory factory analysis.

Before conducting exploratory factor analysis, item analysis was first conducted to exclude 
particular items that were not congruent with others and this contributes to the improvement of the reliability of items. Critical ration method was used and nine items (h4, h23, h21, h7, h24, h22, h28, h25, h26) were therefore deleted. Then Cronbach Alpha, which provides a coefficient of inter-item correlations and is a measure of internal consistency among the items, was calculated to find out how reliable it is for data collection. It found out Cronbach Alpha of the PPE scale is 0.86 and according to the reliability level is acceptable at 0.8 .

Two parallel factor analyses that included 19 influence variables were then conducted. The first analysis was conducted on 301 cases which were randomly selected from the sample and the second analysis was conducted using the other half remaining sample. The results were essentially identical. These analyses consistently resulted in three factors with eigenvalues grater than 1.0 and the three factors accounted for $55.537 \%$ percent of variance (see Table 3 ).

Tab.3 Summary of Exploratory Factor Analysis of PPE Scale of Translator Training

\begin{tabular}{|c|c|c|c|c|c|}
\hline \multirow{2}{*}{ Common Factor } & \multirow{2}{*}{ Item } & \multirow{2}{*}{ Variance $(\%)$} & \multicolumn{3}{|c|}{ Factor } \\
\hline & & & 1 & 2 & 3 \\
\hline \multirow[t]{5}{*}{ Teaching Environment } & h19 & \multirow[t]{5}{*}{21.208} & .860 & & \\
\hline & h17 & & .786 & & \\
\hline & h18 & & .765 & & \\
\hline & h20 & & .756 & & \\
\hline & h16 & & .731 & & \\
\hline \multirow[t]{6}{*}{ Institutional Environment } & h10 & \multirow[t]{6}{*}{18.582} & & .736 & \\
\hline & h11 & & & .693 & \\
\hline & h9 & & & .647 & \\
\hline & h14 & & & .630 & \\
\hline & $\mathrm{h} 8$ & & & .630 & \\
\hline & h13 & & & .568 & \\
\hline \multirow[t]{5}{*}{ Social Environment } & $\mathrm{h} 2$ & \multirow[t]{5}{*}{15.747} & & & .732 \\
\hline & h3 & & & & .716 \\
\hline & h1 & & & & .691 \\
\hline & h5 & & & & .687 \\
\hline & h6 & & & & .611 \\
\hline \multicolumn{2}{|l|}{ Eigenvalue } & & 3.393 & 2.973 & 2.520 \\
\hline
\end{tabular}

Structure equation modeling (SEM) methods were used to check the validity of the questionnaire. The goodness-of-fit of the models was evaluated using absolute and relative indices. The absolute goodness-of-fit indic calculated was the Root Mean Square Error of Approximation (RMSEA). Values smaller than .08 for RMSEA are indicative of an acceptable fit, and values greater than 0.1 should lead to model rejection. Besides, as recommended other relative goodness-of-fit indices are also computed. They are (a) the Comparative Fit Index (CFI), a population measure of model misspecification that is particularly recommended for model comparison purposes; and (b) the Tucker-Lewis Index (TLI), which is a relative measure of covariation explained by the model that is specifically developed to assess factor models. For both relative fit indices, as a rule of thumb, values greater than .90 are considered as indicating a good fit. The details of goodness-of-fit indices are in Table 4 and it can be found that the construct validity of the instrument is quite satisfactory.

Tab.4 The Fit of the PPE Model for Translator Training

\begin{tabular}{cccccc}
\hline Goodness-of-fit indices & RMSEA & GFI & AGFI & TLI & CFI \\
\hline Criteria & $<.08$ & $>.90$ & $>.90$ & $>.90$ & $>.90$ \\
Values of PPE Model & .057 & .923 & .920 & .945 & .954 \\
\hline
\end{tabular}

\section{Descriptive statistics of the PPE of translator training}

To answer the first research question, the descriptive statistics of the perceptions of the students of seven MTI programs need to be presented. The mean of PPE is 3.4075 and it reflects that the status quo of PPE is acceptable but still needs to be improved. Comparatively speaking the condition of teaching environment (mean=3.915) is better than that of institutional environment 
(mean=3.477) and social environment (mean=2.815). A close look at the mean of each particular item revealed that the mean of Item $\mathrm{h} 2$ is only 2.510 , and $60 \%$ subjects either disagree or strongly disagree with this statement. As to the social status of translators over half $(57.8 \%)$ disagree or strongly disagree with Item $\mathrm{h} 3$. And less than one fifth agree that employers are actively involved in translator training (h5).

In contrast to the poor social environment the teaching environment is encouraging. A large majority $(89.3 \%)$ of respondents agrees or completely agrees that faculty of MTI program are serious with the teaching (h19), and also they agree or completely agree that faculty pay enough attention to teaching (h18). As to the academic qualifications of the faculty over two thirds of respondents $(78.4 \%)$ think their educational credentials are high.

\section{Independent sample $t$ test and ANOVA}

To answer the second research question the independent sample $\mathrm{t}$ test and ANOVA were conducted and the results are in Table 5 and Table 6.

Tab.5 Summary of Independent Sample T Test

\begin{tabular}{|c|c|c|c|c|c|c|c|}
\hline Variable & Group & Total & Mean & SD & $\begin{array}{c}\text { Mean of Standard } \\
\text { Error }\end{array}$ & $\mathrm{T}$ & $\mathrm{P}$ \\
\hline \multirow[t]{2}{*}{ Gender } & Female & 506 & 54.68 & 7.938 & .353 & 1.044 & 207 \\
\hline & Male & 96 & 53.72 & 9.771 & .997 & & . 291 \\
\hline \multirow[t]{2}{*}{ Duration of Program } & $2.5 \mathrm{yrs}$ & 194 & 53.81 & 8.904 & .639 & & \\
\hline & $3 \mathrm{yrs}$ & 408 & 54.87 & 7.918 & .392 & -1.468 & .143 \\
\hline Major of First & Non-English & 74 & 53.82 & 8.415 & 978 & -.779 & 136 \\
\hline Degree & English & 528 & 54.62 & 8.237 & .358 & & .456 \\
\hline \multirow[t]{2}{*}{ Type of Institution } & Comprehensive & 275 & 54.76 & 8.373 & .505 & 650 & .516 \\
\hline & Foreign Studies & 327 & 54.32 & 8.165 & .452 & & \\
\hline Location of & West China & 270 & 54.29 & 7.911 & 481 & -.632 & 527 \\
\hline Institution & East China & 332 & 54.72 & 8.534 & .468 & & \\
\hline
\end{tabular}

Tab.6 Summary of ANOVA Analysis

\begin{tabular}{|c|c|c|c|c|c|c|c|}
\hline Varible & & $\begin{array}{l}\text { Sum of } \\
\text { Squres }\end{array}$ & df & $\begin{array}{l}\text { Mean of Sum } \\
\text { of Squares }\end{array}$ & F test & Scheffe & Tamhane \\
\hline \multirow[t]{3}{*}{ Study Year } & Between Groups & 2412.882 & 2 & \multirow{3}{*}{$\begin{array}{c}1206.441 \\
64.366\end{array}$} & \multirow[t]{3}{*}{$18.743^{* * \pi}$} & & \multirow{6}{*}{$\begin{array}{l}A>B \\
A>C\end{array}$} \\
\hline & Within Group & 38555.244 & 599 & & & & \\
\hline & Total & 40968.126 & 601 & & & & \\
\hline English & Between Groups & 10.033 & 1 & 10.033 & \multirow[t]{3}{*}{.147} & \multirow[t]{3}{*}{ n.a. } & \\
\hline \multirow[t]{2}{*}{ Proficiency } & Within Group & 40958.093 & 600 & 68.263 & & & \\
\hline & Total & 40968.126 & 601 & & & & \\
\hline \multirow{2}{*}{$\begin{array}{l}\text { Satisfaction } \\
\text { of Program }\end{array}$} & Between Groups & 9670.592 & 2 & \multirow{2}{*}{$\begin{array}{c}4835.296 \\
52.250\end{array}$} & \multirow[t]{2}{*}{92.542} & & \multirow{2}{*}{$\begin{array}{l}B>A \\
C>A\end{array}$} \\
\hline & Within Group & $\begin{array}{l}31297.535 \\
40968.126\end{array}$ & $\begin{array}{l}599 \\
601\end{array}$ & & & & \\
\hline
\end{tabular}

Note: $\mathrm{n} . \mathrm{a}$ means $\mathrm{p}>0.05 ; * *$ means $\mathrm{p}<0.001$

It shows that there is no statistically significant difference in gender, duration of program, major of first degree, type of institution, location of institution in terms of students' perceptions. In other words the perceptions of the students of the PPE are quite similar regardless of where and what types and how long the MTI program is. The result of ANOVA analysis reveals that there is significant difference between Year One and the other two groups (Year Two and Year Three). This may have something to do with the fact that Year One students are new to the institution and may be still in their honey-moon period and tend to over rate everything of the university that they applied for and were admitted to. Another interesting finding is that those students who are satisfied with their learning experience tend to think highly of their MTI programs. This may shed some light on the importance and the need of providing a better learning experience for students. And the last finding is that there are no statistically significant differences in variables of English proficiency and their knowledge of the profession when comparing the students' perceptions. Linguistic competence and knowledge of the profession do not seem to play a role in perceiving the PPE. 


\section{Conclusion}

The study presented here applied the theory of professional education and surveyed the PPE of translator training in China. The findings include:

The PPE of translation training of China consists of three factors, namely social environment, institutional environment and teaching environment.

Of the three factors the social environment is in a quite worrisome condition, especially the salary and social position of translators. Teaching environment is much satisfactory compared with the state of the social environment and that of institution.

The perceptions of the students of the PPE are quite similar regardless of where and what types and how long the MTI program is.

There is significant difference between Year One and the other two groups (Year Two and Year Three) in their perceptions of PPE.

\section{Acknowledgments}

The research was financially supported by the research funding of National Advisory Council for MTI Education (Grant No. MTIJZW201412), Department of Education of Shaanxi Government (Grant No. 2015JK0407), and Northwest University (Grant No. JX14071, and JK14026).

\section{References}

[1] Information on http://usuaris.tinet.cat/apym/on-line/training/ 1998_training_institutions.pdf.

[2] Y. Tao, Towards a constructive model: A case study of MTI education program in China, Babel 3(2012) 289-307.

[3] Information on http://cnmti.gdufs.edu.cn/hydw/153.html.

[4] L. Mu, W. Zhong and W. Wang, Reflection on Current Translator and Interpreter Education: From the Perspective of Professionalization, Foreign Languages in China 1(2013) 89-95.

[5] Information on http://translation journal.net/journal/15training.htm.

[6] D. Li, Translator Training: What Translation Students Have to Say, Meta 4(2002) 513 - 531.

[7] J. Liu, Translators Training: Teaching Programs, Curricula, Practices, Journal of Language Teaching and Research 1(2013) 127-132.

[8] J. S. Stark, A Conceptual Framework for the Study of Pre-service Professional Programs in Colleges and Universities, The Journal of Higher Education 3(1986) 231-258.

[9] A. J. Threlkeld, G. M. Jensen and C. B. Royeen, The Clinical Doctorate: A Framework for Analysis in Physical Therapist Education, Physical Therapy79 (1999) 567-581. 